\title{
Solar Energy for Rural Madagascar Schools: A Pilot Implementation by University of Nebraska Engineers Without Borders-USA
}

\author{
Benjamin J. Pavlik \\ Department of Chemical and Biomolecular Engineering \\ University of Nebraska, Lincoln
}

Ian C. Parsley

Department of Biological Systems Engineering

University of Nebraska, Lincoln

\section{Zoelitiana Ndrianajasoloarivony \\ École Normale Supérieure \\ Antananarivo, Madagascar}

\author{
Shannon L. Bartelt-Hunt \\ Department of Civil Engineering \\ University of Nebraska, Lincoln
}

\author{
Jodi L. Sangster \\ Department of Civil Engineering \\ University of Nebraska, Lincoln \\ Erik M. Knudsen \\ Department of Mechanical and Materials Engineering \\ University of Nebraska, Lincoln \\ Dean J. Patterson \\ Department of Electrical Engineering University of \\ Nebraska, Lincoln \\ Elizabeth G. Jones \\ Department of Civil Engineering \\ University of Nebraska, Lincoln \\ Contact: Libby.Jones@unl.edu
}

\begin{abstract}
A pilot photovoltaic system was constructed in Kianjavato, Madagascar by a team from the University of Nebraska Engineers Without Borders-USA Student Chapter. This project represents an integrated approach to energy supply, education and natural resource conservation. The system supplies power to ten $13 \mathrm{~W}$ fluorescent tubes in a primary school classroom for the purpose of extending public school hours into the evening for adult education. The project was implemented in partnership with a Malagasy nongovernmental organization, the Madagascar Biodiversity Partnership. Future monitoring data will determine the outcome of the project and aid in the design of additional installations in the community.
\end{abstract}

Index Terms - Engineers Without Borders, international engineering, Madagascar power supply, off-grid, photovoltaic, solar power

\section{INTRODUCTION}

Almost 1.3 billion people in the developing world, representing one fifth of the world's population, do not have access to modern electricity in their homes ${ }^{1}$. Rural sub-Saharan Africa is ranked lowest for access to electric power at an electrification rate of $14.2 \%^{2}$. In 2009, Madagascar generated 1.35 billion $\mathrm{kWh}$ for use by 20.12 million people, resulting in $67.1 \mathrm{kWh}$ per capita. By comparison, the United States generated over $12,000 \mathrm{kWh}$ per capita the same year ${ }^{2,3,4}$. Poverty in Madagascar increased by 4 million people between 2008 and 2009 due to a combination of population growth and political turmoil ${ }^{5}$. A decline in both infrastructure and quality of life has resulted, severely limiting socioeconomic development. Engineers Without Borders - USA (EWB-USA) provides engineering expertise to deliver small- scale infrastructure 
projects by cooperating with developing communities. The University of Nebraska Student Chapter (EWB-NU) has been working to develop customized solutions for power and water supply in the community of Kianjavato, Madagascar.

Kianjavato is a rural commune of approximately 10,000 people spread over an area of $100 \mathrm{~km}^{2}$ near the eastern coast of Madagascar, approximately 724 kilometers south of Antananarivo (Figure 1). It consists of several groupings of small communities called fokontany. The primary fokontany is also called Kianjavato, and is adjacent to an unprotected forest that serves as the primary remaining habitat for the Greater Bamboo Lemur. Severe deforestation in the area is attributed to marginal rice farming, firewood harvesting and charcoal production. Many residents of Kianjavato understand that sustaining biodiversity through conservation efforts ultimately benefits the commune economically. However, lack of sustainable infrastructure increases the dependency on natural resources extracted from the adjacent lands.

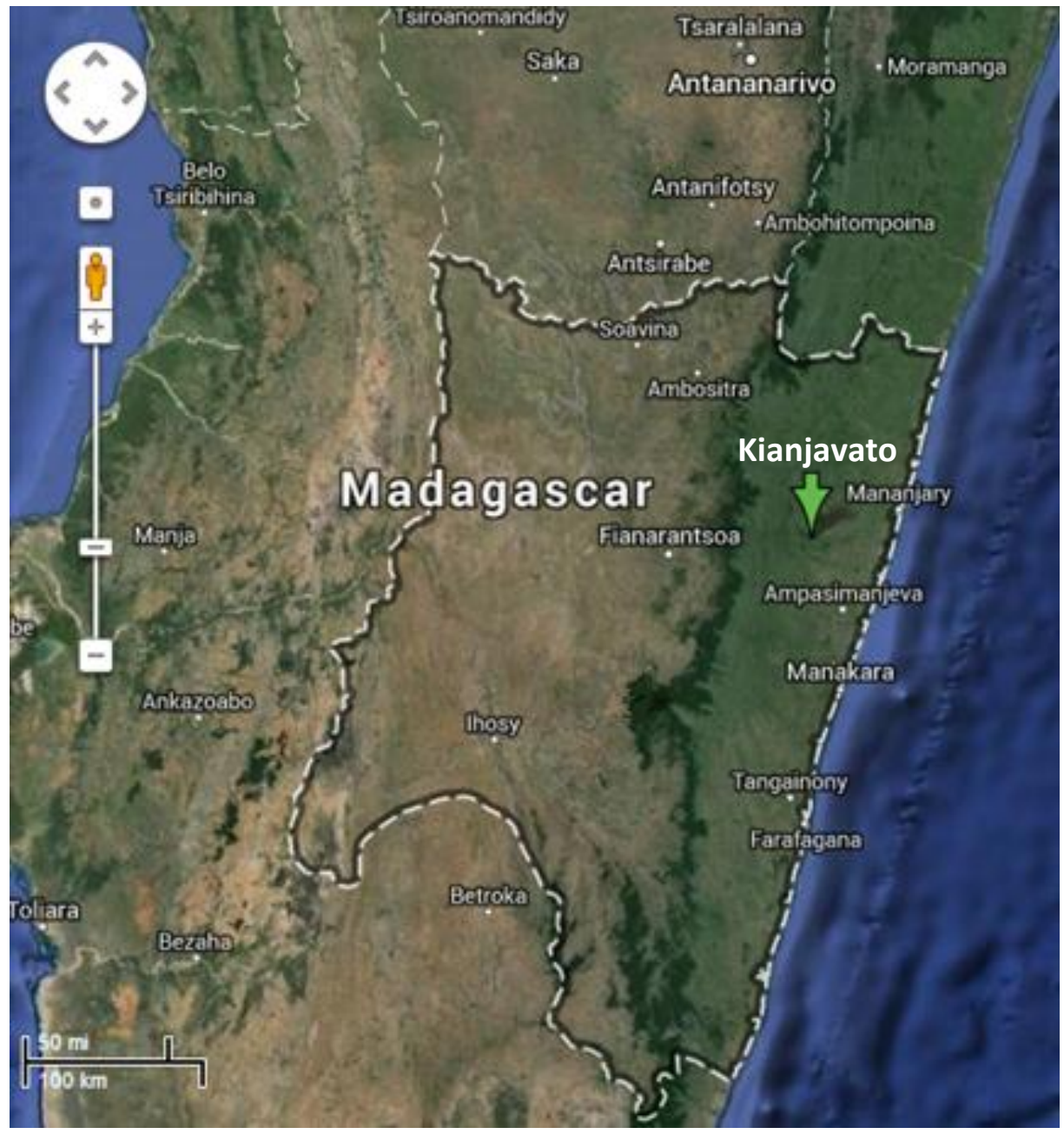

FIGURE 1

THE GREEN ARROW ABOVE DISPLAYS THE LOCATION OF THE KIANJAVATO COMMUNE IN RELATION TO MAJOR CITIES WITHIN MADAGASCAR ${ }^{6}$ 
During an assessment trip in May 2010, the mayor, schools superintendent and residents of Kianjavato indicated that access to electricity was their highest priority when project choices were unlimited. Electricity was favored over clean water by the community, an indication of the desire to charge cell phones and have lighting at night. After further investigation, we found the commune generally lacked the means to provide power for itself. Gas and diesel-powered generators are impractical due to the high cost of fuel and only the wealthiest residents own them. The mayor also indicated that there were no plans for transmission lines to connect the commune with the nearest areas of central power, those being Ranomafana (located $\sim 50 \mathrm{~km}$ west of the Kianjavato commune on the road to Fianarantosa) and Manajary ( $75 \mathrm{~km}$ northeast of the Kianjavato commune). The superintendent of the public school system, Chef ZAP (Zone d'Action Pedagogique. Translation - chief of a pedagogical work area), became our primary community leader contact. As a well-respected leader having previously worked with EWB-NU associated programs, he provided access to a politically neutral institution that also creates an educational opportunity for the community as a whole. Chef ZAP and the school teachers where solar was installed are committed to their responsibility of maintenance and operations, including costs incurred during these activities. EWB-NU signed a memorandum of understanding with the community to power seven of the community's schools located on-road (Figure 2). Off-road schools have been assessed, but present logistical challenges that have yet to be addressed.

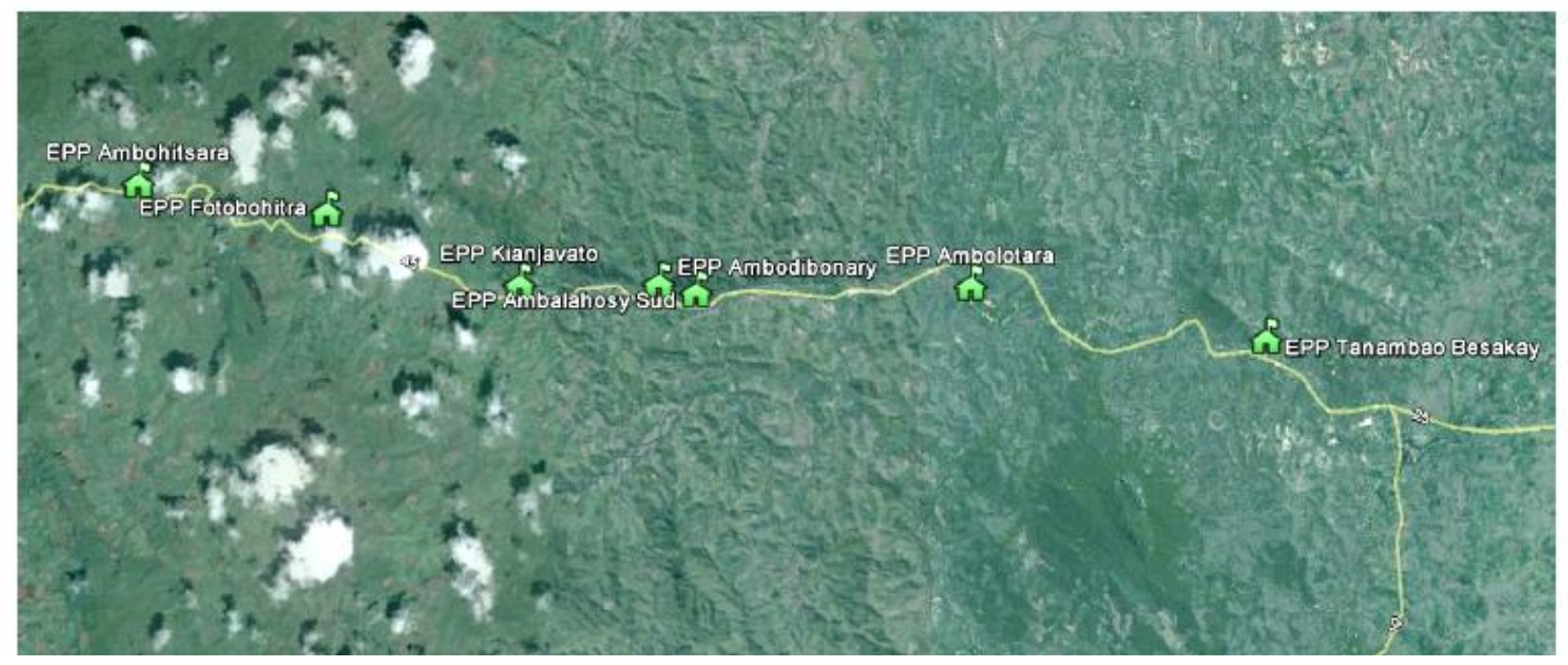

FIGURE 2

THE LOCATIONS OF CURRENT AND PLANNED POWER SUPPLY INSTALLATIONS AT SCHOOLS WITHIN THE KIANJAVATO COMMUNE ${ }^{7}$

An important part of the EWB-USA development model is that projects are sustainable and community driven. This type of holistic approach is preferable to focusing solely on supply of energy or on a particular technology ${ }^{8}$. The community makes choices with regards to power supply and becomes familiar with the technology for the purposes of social acceptance and operation. EWB-NU participants found that the local medical clinic had a solar powered refrigerator and lights. In addition, Chef ZAP had already acquired a small solar power system through a Malagasy government program to drive the school's computer, TV and DVD. This 
system had previously been powered by a very costly gas generator, leaving it essentially unused.

Although solar energy seemed to be the communities' preference for providing power simply because of familiarity, EWB-NU did evaluate other alternatives for use in Kianjavato schools. Geothermal, solar, wind, biomass, pico/micro-hydroelectric, human power and diesel generators were considered. A "do nothing" alternative was also evaluated. Table I compares criteria such as constructability, operations and maintenance, quantity of power generated, ease of use and sustainability for evaluating each of these options. The criterion of immediate feasibility considered the resources available to Kianjavato and EWB-NU, such as investment, time, expertise required, and efficacy of the technology. Solar power was chosen as the preferred alternative due to a high immediate feasibility, constructability, low operating and maintenance costs, flexibility in design for demand and sustainability. Sustainability was defined by social acceptance, environmental harm, education, theft potential and scalability. Initial cost and continuity of power generation were obstacles to be further investigated by EWB-NU.

\section{TABLE I}

TECHNOLOGY OPTIONS FOR PROVIDING POWER TO SCHOOLS WITHIN KIANJAVATO WERE SCORED ACCORDING TO CRITERIA RESEARCHED BY EWB-NU

\begin{tabular}{|c|c|c|c|c|c|c|c|}
\hline & Geothermal & Solar & Wind & Biomass & $\begin{array}{c}\text { Pico/Micro } \\
\text { Hydro-Electric }\end{array}$ & $\begin{array}{l}\text { Human } \\
\text { Power }\end{array}$ & $\begin{array}{c}\text { Diesel } \\
\text { Generator }\end{array}$ \\
\hline \multicolumn{8}{|l|}{ Feasibility } \\
\hline Immediate Feasibility & 1 & 3 & 2 & 1 & 2 & 3 & 3 \\
\hline Long-Term Feasibility & 2 & 2 & 2 & 2 & 3 & 1 & 2 \\
\hline \multicolumn{8}{|l|}{ Construction/Implementation } \\
\hline Skills Required & 1 & 2 & 2 & 1 & 1 & 3 & 1 \\
\hline Material Availability & 1 & 2 & 2 & 2 & 2 & 2 & 1 \\
\hline Time Required & 1 & 2 & 2 & 1 & 1 & 3 & 1 \\
\hline Distribution & Grid & Point & Grid & Grid & Grid & Point & Grid \\
\hline Initial Cost & 1 & 1 & 2 & 1 & 2 & 3 & 3 \\
\hline \multicolumn{8}{|c|}{ Operations/Maintenance/Replacement } \\
\hline Skills Required & 1 & 2 & 2 & 2 & 3 & 3 & 1 \\
\hline Time Required & 3 & 3 & 2 & 1 & 3 & 1 & 2 \\
\hline Operating Cost & 3 & 3 & 3 & 1 & 3 & 3 & 1 \\
\hline Replacement Cost & 1 & 1 & 2 & 1 & 2 & 3 & 1 \\
\hline Lifespan & 3 & 2 & 2 & 2 & 3 & 3 & 2 \\
\hline Durability & 3 & 1 & 2 & 2 & 3 & 3 & 3 \\
\hline \multicolumn{8}{|l|}{ Power Generation } \\
\hline Maximum Energy Potential & 3 & 2 & 2 & 3 & 2 & 1 & 2 \\
\hline Average Energy Produced & 2 & 2 & 2 & 2 & 2 & 1 & 2 \\
\hline Continuous or Intermittent & Cont. & Inter. & Inter. & Cont. & Cont. & Inter. & Cont. \\
\hline Need For Battery & No & Yes & Yes & No & No & Yes & No \\
\hline \multicolumn{8}{|l|}{ Sustainability } \\
\hline Environmental Harm & 2 & 3 & 3 & 3 & 3 & 3 & 2 \\
\hline Theft Potential & 3 & 1 & 2 & 3 & 3 & 3 & 3 \\
\hline Replicability & 1 & 2 & 2 & 3 & 2 & 3 & 3 \\
\hline \multicolumn{8}{|l|}{ Social Acceptance } \\
\hline Familiarity & 1 & 3 & 2 & 1 & 3 & 1 & 3 \\
\hline Education & 1 & 2 & 2 & 1 & 2 & 3 & 1 \\
\hline
\end{tabular}

Key: 3 - Factor is conducive to project success 2 - Factor is neutral to project success 1 - Factor is not conducive to project success

Community consultations made it clear that the short-term objective of the EWB-NUKianjavato partnership should be providing solar electric power to schools that need evening light for educational programs. Education is seen as important to development by community leaders. After the engineering design process, a photovoltaic (PV) power system would be installed in one classroom at the main primary school. In addition to the benefits to children, the 
pilot project could also support general adult education and give a local non-governmental organization, Madagascar Biodiversity Project (MBP), the opportunity to further promote conservation and reforestation projects with evening educational programs and meetings. MBP originates from Omaha's Henry Doorly Zoo and aided the traveling team. MBP has a permanent field station, the Kianjavato Ahmanson Field Station, located outside Ambalahosy-Sud fokontony. In addition to conducting extensive research on critically endangered lemurs in the area, MBP is actively working with the community on reforestation efforts aimed at increasing lemur habitat. In return for tree planting, the community earns credit towards PV installations by EWB-NU. MBP has also conducted educational programs in the local schools to promote conservation. In the future, ecotourism facilities could also be enhanced by access to power. In total, seven schools will have solar power for lights designed by EWB-NU and installed in partnership with the community. This paper outlines the data collection, design and installation of a solar power and lighting system installed by a team of four EWB-NU students and faculty advisors during a May 2012 implementation trip.

\section{DATA COLLECTION}

Members of EWB-NU collected technical information for the design of a PV system in preparation for a site visit during May 2011. Included was information on the dimensions and load bearing capacity of targeted school buildings, local solar radiation receipts, existing lighting and temperature levels inside and outside of the classrooms, the number of hours classrooms were in use each day, week and year, electrical loads and the availability of supplies and equipment in the region.

The exterior dimensions of each school and the potential for mounting a solar array were measured and assessed with a $100 \mathrm{~m}$ tape and Abney level. In general, the newer concrete block buildings with a concrete skim coat over the exterior appear to have adequate roofs and support to mount the panels. The rafters were either steel I-beams or wood and the joists are wood. The community uses many of these buildings for shelter during tropical cyclones and they appeared to have received little damage from the 2009 cyclone. The roof of the building selected for the initial installation was made of corrugated steel with steel I-beam rafters and wood joists underneath. It was noted that the panel array previously mounted by the Malagasy government was located on this same type of roof structure on a nearby building. Roof mounting required that the roof be oriented so the solar array faced north in the southern hemisphere. The Kianjavato primary school roof slopes at an angle of 6.9 degrees north, making it nearly ideal for mounting the PV array because it is close to the latitude of Kianjavato $\left(21^{\circ} \mathrm{S}\right)$.

During the site visit in May 2011, we installed an Onset (Bourne, MA) HOBO® Weather Station with U30-NRC data logger, 2 meter tripod mounting kit, $1.2 \mathrm{~W}$ solar panel, wind speed and direction sensor, temperature and relative humidity sensor with solar radiation shield, tipping bucket rain gauge, and solar radiation sensor (silicon pyranometer). About once a month, these data were downloaded by a member of MBP and sent to us via email once internet access was established. After collection of the measured data, the solar insolation was found to be slightly lower than predicted by NASA (Table II), due to the effects of local weather versus the satellitebased large area average (one-degree longitude by one-degree latitude) provided by NASA. The local data had also been extremely variable from month to month and year to year, so we chose to use the lowest measured irradiance values when calculating the required size of our system. 
We used the July 2011 value of $3.64 \mathrm{kWh}^{1} \mathrm{~m}^{-2}$ day $^{-1}$ on a horizontal surface for our anticipated minimum insolation when designing the power system.

TABLE II

COMPARISON OF NASA DAILY SOLAR ENERGY RECEIPTS AVERAGED PER MONTH WITH KIANJAVATO EWB-NU WEATHER STATION DATA BETWEEN 2011 AND 2012

\begin{tabular}{cccccccccccccc}
\hline & Jan & Feb & March & April & May & June & July & Aug & Sept & Oct & Nov & Dec \\
& 2012 & 2012 & 2012 & 2012 & 2011 & 2011 & 2011 & 2011 & 2011 & 2011 & 2011 & 2011 \\
\hline NASA $^{9}$ & 5.74 & 5.55 & 5.22 & 4.74 & 4.08 & 3.82 & 3.93 & 4.74 & 5.75 & 6.09 & 6.27 & 6.00 \\
EWB-NU $^{4.29}$ & 5.22 & 4.50 & 3.98 & 3.59 & 3.67 & 3.64 & 3.72 & 4.66 & 4.44 & 5.29 & 5.55 \\
\hline
\end{tabular}

All values in $\mathrm{kWh}^{1} \mathrm{~m}^{-2} \mathrm{day}^{-1}$ on a horizontal surface

To measure the existing lighting and temperature levels in the classrooms, we installed Hobo® (UA-002-64K) light/temperature sensors from Onset ${ }^{\circledR}$. We purchased 20 of these, each with enough storage to record hourly lighting and temperature levels every hour for four months. We installed one sensor inside each of the classrooms at the Kianjavato primary school, one sensor in each of the buildings at the Kianjavato secondary school and one sensor at each of the other schools. Outside shading and temperature measurements were made with a Solar Pathfinder ${ }^{\circledR}$ (Linden, TN) and the weather station, providing data on the percentage of unobstructed sky and the daily average hours of sun over the year. At the lowest point of the roof $95.2 \%$ of the solar window was un-shaded. It was noted that if the solar panels were located higher on the roof the percent shading would be even lower due to lack of trees near the building. Figure 3 shows the location of the initial solar shading measurement.

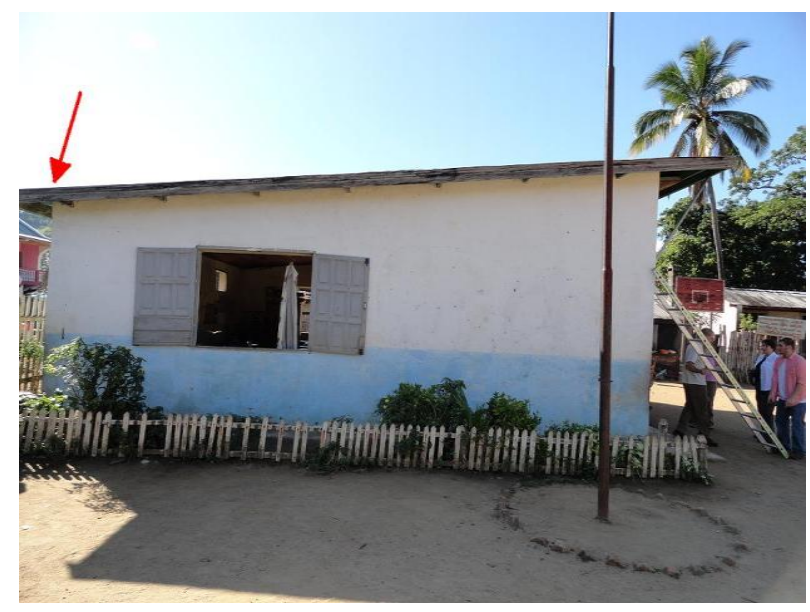

FIGURE 3

THE ARROW INDICATES THE LOCATION OF THE INITIAL SOLAR INSOLATION MEASUREMENTS ON THE PRIMARY SCHOOL

According to Chef ZAP, classrooms are generally used each day from 7 am to $5 \mathrm{pm}$. School is in session during the week Monday through Friday and operates on a trimester system with breaks for Christmas and Easter. A two month break for "summer holidays" occurs during the southern hemispherical winter. 
Another important objective of the May 2011 assessment trip was to ascertain the supplies and equipment availability in Madagascar. The team was able to visit two hardware stores, one electrical supply store, and two solar firms in the capital city, Antananarivo. It was encouraging to learn that most electrical supplies and solar power equipment were readily available incountry. Additionally, Sanifer Electric $®$ carried a line of supplies from an internationally known company, Schneider Electric ${ }^{\circledR}$. Tenesol ${ }^{\circledR}$ was chosen as the provider of solar power equipment in Antananarivo.

\section{DESIGN OF THE SOLAR POWER SySTEM}

The primary school in Kianjavato was chosen at the pilot site in consultation with community leaders and from a technical feasibility standpoint. This school is on the road in the center of Kianjavato and the largest primary school. For security and discouragement of misuse, the PV system would be located close to Chef ZAP's home inside the Kianjavato primary school fences. Installing at this centralized location would also avoid the perception of favoritism. The Kianjavato primary school would structurally support a PV implementation as well as provide sufficient solar access. Figure 4 shows the interior of the building.

The calculations used to design this system have been taken from the Solar Energy Institute (SEI) ${ }^{10}$. Conservatism was employed in the choice of solar insolation values used and sizing of the system components. The design herein describes lighting requirements, load calculations, PV array sizing, batteries, the charge controller, wire sizing, structural analysis related to roof mounting and monitoring.

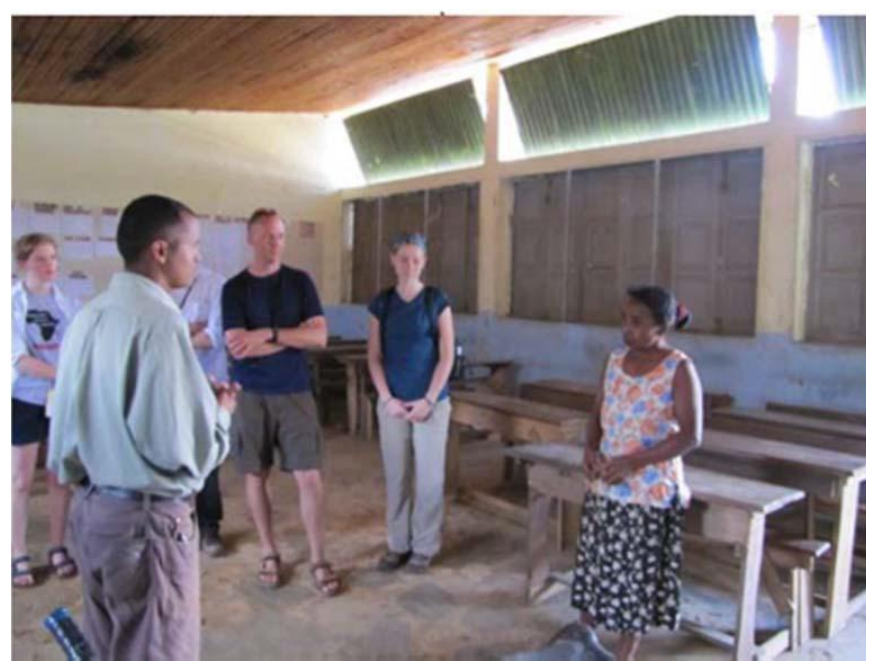

FIGURE 4

DURING THE INITIAL ASSESSMENT TRIP, EWB-NU MEMBERS CONSULTED WITH SCHOOL OFFICIALS INSIDE THE PILOT SITE BUILDING

\section{Electrical Load Calculation}

The amount of power required for the lighting system was calculated by determining the number of hours the system would be used and the power demands of the lights. Chef ZAP asked that 
the system support weekday night classes, so a minimum of four hours of use per weekday were assumed.

Rural household lighting installations in Nepal have provided 25 lux for general use and 112 lux for reading ${ }^{11}$. In comparison, the US standard for lighting classrooms in 1918 was 37.7 to 64.5 lux, pushed towards 107.6 lux in libraries by General Electric's Edison Lamp Works ${ }^{12}$. EWB-NU chose 107.6 lux as its target light intensity. The Zonal Cavity method was used to find the required number of luminaries based on the characteristics of the classroom and the target light intensity ${ }^{13}$. This load calculation, along with weather data, guided the design of the system. For this classroom, four $32 \mathrm{~W}, 12 \mathrm{~V}$ fluorescent tubes were selected for a total of $128 \mathrm{~W}$, and a $512 \mathrm{Wh}$ load per day (Figure 5).

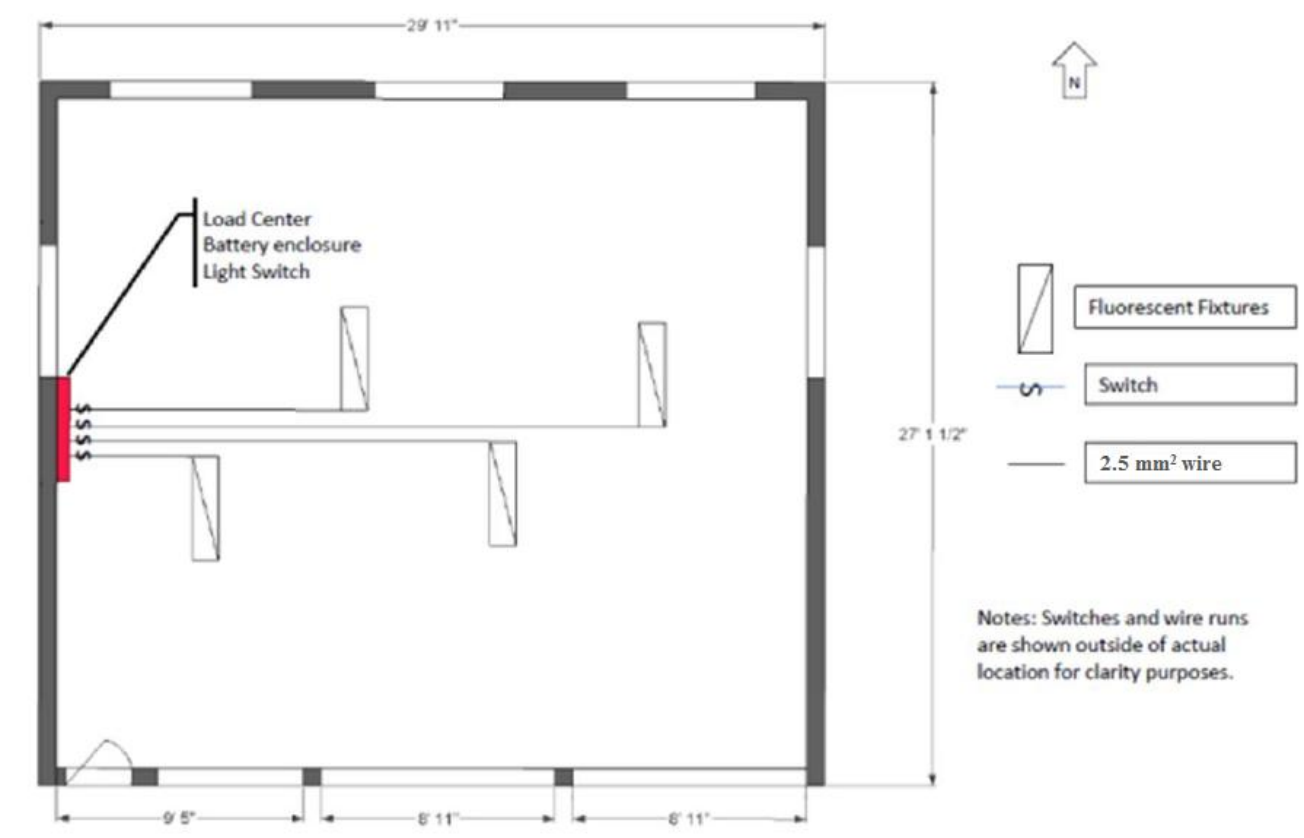

FIGURE 5

PLANNED LOCATIONS OF FLUORESCENT TUBES AND ELECTRONICS WERE CHOSEN TO MAXIMIZE LUMINANCE AND SAFETY FOR STUDENTS

\section{PV Module Sizing and Wiring}

The number and size of solar panels required was determined by the SEI specifications, input from mentors and available equipment. Two $135 \mathrm{~W}$ PV modules (Tenesol® TE1300) were wired in series to maximize the efficiency of the maximum power point tracking (MPPT) feature of the selected charge controller. If the panels were wired in parallel, damage to a single panel would not sacrifice the functionality of the system. However, as a pilot project, operational efficiency was favored over the risk of damage. 


\section{Batteries}

Two deep cycle 12 V, 100 Ah (Virio Batterie Solaire) lead acid batteries designed for solar applications were chosen. Car batteries are known to have poor field performance with PV applications due to undersized storage applications ${ }^{14}$. Lead acid batteries have the added advantage of being familiar to the community in terms of maintenance, and as they are manufactured in Madagascar they can be readily recycled. The batteries are wired in parallel to ensure $12 \mathrm{~V}$ is maintained over the terminals, ensuring compatibility with the lights in the system. The voltage choice also provides a safer classroom environment with little potential for harmful shocks.

The battery bank was sized to provide two days of autonomy at the average daily power consumption of $512 \mathrm{Wh}(42.7 \mathrm{Ah})$ with a discharge limit of $50 \%$ to prolong battery life. It is important to note that repeated use of the system for periods longer than four hours may result in depletion of the battery beyond the discharge limit when used in cloudy weather. A relay, discussed in the charge controller section, was incorporated to shut off power if this limit is reached, allowing use during the day or evening, but not both.

We calculated the days of absolute system autonomy and a weather-predicted depth of battery discharge. Autonomy was defined as duration of anticipated operation with zero solar input to the system. While the system was designed with two days of autonomy under maximum loading, it will actually perform for two to five days using all or half the lights, depending on the degree and frequency of cloudiness. The battery depth of discharge on a weekly usage basis (4 hours per day, 5 days per week) under different weather scenarios and loadings is shown in Figure 6. Weather station data allowed this realistic calculation of days of system autonomy and predicted depth of battery discharge. Daily solar radiation below the conservative design criteria of $3.21 \mathrm{kWh}^{1} \mathrm{day}^{-1}$ was considered a cloudy day, and all accumulated data points below this threshold were averaged to $2.83 \mathrm{kWh}^{1} \mathrm{day}^{-1}$. One standard deviation from this cloudy day average was also considered $\left(2.15 \mathrm{kWh}^{1} \mathrm{day}^{-1}\right)$. The battery bank would be able to supply $73 \%$ more power than the estimated daily loads while still remaining above the discharge limit of our design criteria. Under normal operating conditions equal to or better than our lowest average monthly solar insolation, the battery bank will cycle at a $21 \%$ discharge rate. 
Battery Bank Weekly Depth of Discharge During Anticipated Hours of Use Under Maximum (512 Wh) and One-Half System Loads (256 Wh)

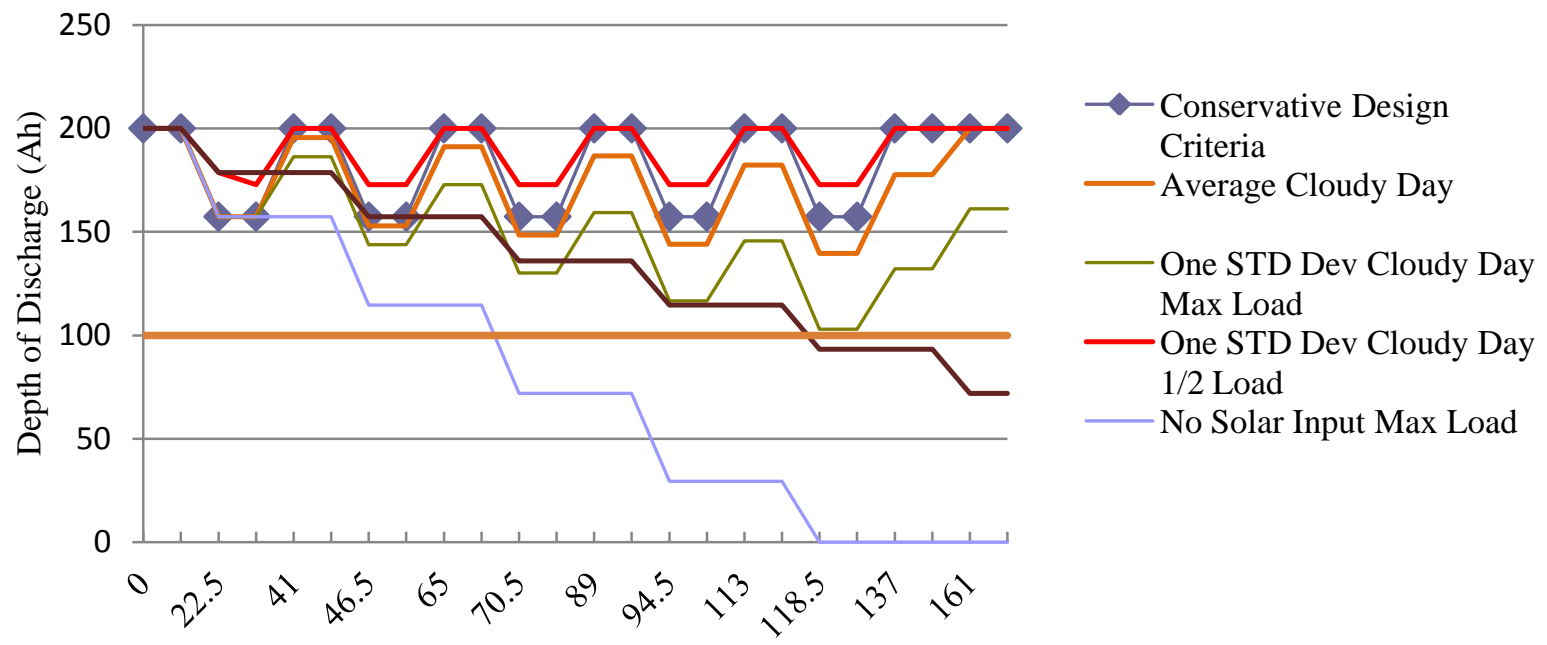

Hour of the Week With 4 Hours Evening Use $\mathrm{x}$-intercept corresponds to 12:00 AM Monday

FIGURE 6

DEPTH OF DISCHARGE ANALYSIS ENSURES THAT THE BATTERY BANK IS SUFFICIENT FOR AUTONOMOUS USE DURING CLOUDY WEATHER

\section{Charge Controller}

The chosen MPPT charge controller (Schneider Electric ${ }^{\circledR}$ Xantrex XW MPPT60) has a maximum input capacity of $60 \mathrm{~A}$ and $150 \mathrm{~V}$ from the array. It collects data and stores 30 daily $\operatorname{logs}$ that are converted into a monthly total, with up to 12 months stored. The controller can be used in conjunction with $12,24,36,48$, or 60 volt DC battery systems. It is also able to charge a lower nominal voltage battery from a higher nominal voltage array, providing flexibility for postinstallation modifications. The $60 \mathrm{~V}$ maximum is higher than the PV operational voltage of $44.88 \mathrm{~V}$, so the controller will not become overloaded.

Additionally, the charge controller has a programmable monitoring and auxiliary power feature that can be used to ensure the battery is not over-discharged (Figure 7). The programmable auxiliary power output of 5-13 V DC at $200 \mathrm{~mA}$ is used to trip a relay (Schneider Electric $\left.{ }^{\circledR} 781 \mathrm{XAXC}-12 \mathrm{D}\right)$ to open the circuit when the battery is at the $50 \%$ discharge limit. The low battery trigger can be set to any reasonable voltage and the system will resume normal operation once the battery voltage surpasses the set-point. The relay is a hard cutoff, shutting down all power usage when tripped. This relay has sufficient capacity for this operation and has low $(0.7 \mathrm{~W})$ power dissipation. The relay was attached to a relay socket (Schneider Electric ${ }^{\circledR}$ 70-781D5-1A) allowing for easy terminal connections. 


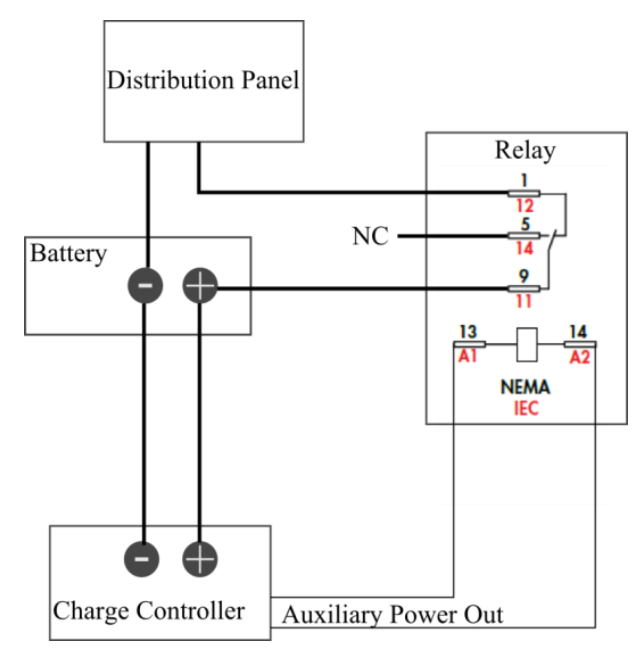

FIGURE 7

A RELAY WAS ADDED TO THE SYSTEM TO ENSURE THAT THE BATTERIES DO NOT BECOME OVER-DISCHARGED

\section{Wiring}

The three-wire diagram for the system is shown in Figure 8. Wire runs are minimized to reduce losses from voltage drop in addition to lowering cost. Wire sizes were computed based on safety considerations and voltage drop requirements (specifications following SEI). While wires selected were larger than required to ensure safe use of the system, they were necessary to improve efficiency and operation. All wires from the PV panels to the load center have a crosssectional area of $6 \mathrm{~mm}^{2}$ and segments from the DC load center to the lights have a cross-sectional area of $2.5 \mathrm{~mm}^{2}$. However, when our design criteria called for a $2 \%$ voltage drop, this was cumulative for each segment in the system. For example, our design allowed a $2 \%$ loss from the PV panels to the controller in addition to the $2 \%$ lost from the controller to the battery. In actuality, the system has a $2 \%$ voltage drop from the PV panels to the load center. This is standard design practice for this type of system. Considering voltage drop through the entire system, there is a voltage drop of $5 \%$ depending on the lights being utilized. While the system may work with an increased voltage drop beyond 5\%, we did not exceed this value.

The lights are wired in parallel allowing separate, modular control as well as the use of smaller gauge wires to reduce voltage drops. We feel it is important to provide as many options for lighting as possible, because electrical power is relatively new to the community. By providing flexibility in this design in the form of maximum lighting control, the users can be more active in energy conservation practices and prevention of over-discharge. 


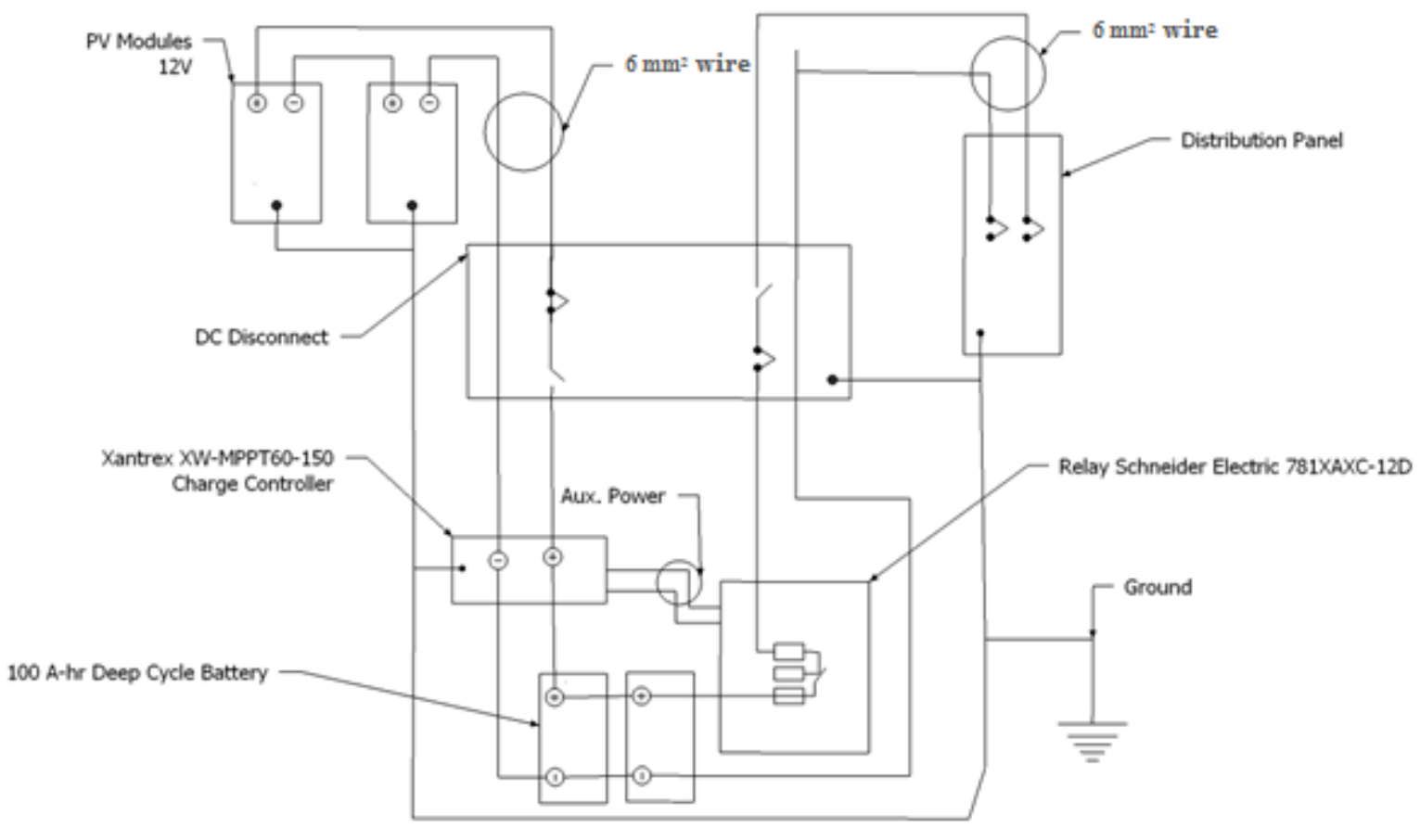

FIGURE 8

THIS THREE WIRE DIAGRAM DESCRIBES THE SPECIFIC WIRING CONNECTIONS OF THE SYSTEM

\section{PV Array Mounting}

One of the most important issues in the design of PV arrays on roofs is the structural attachment of the mounting system to the structural members. The PV array may encounter several types of loading on the roof. Primary load types include dead loads and live loads. The design of the modules and the mounting system must withstand these forces and comply with applicable building codes and standards.

Dead loads are static, the combined weight of the arrays and support structure. These are typically minimal, no more than $245-490 \mathrm{~N} / \mathrm{m}^{2}$. However the loads are often transferred to the roof through the mounting devices that concentrate the array dead loads onto small surface areas or individual load-bearing members. The dead loads of our system are due to the weight of the PV modules and the support structure. The modules weight $127.4 \mathrm{~N}$ each for a total of $254.8 \mathrm{~N}$. We assumed the weight of the mounting structure would be no more than the weight of one PV module, with a combined weight of approximately $490 \mathrm{~N}$. The area over which this dead load would be situated was that of the PV modules $\left(2.04 \mathrm{~m}^{2}\right)$. This gives a dead load of approximately $240.1 \mathrm{~N} / \mathrm{m}^{2}$, which is considered to be minimal.

Live loads can be large in magnitude, but are intermittent and attributed to the effects of wind and the activities of maintenance personnel. Wind loading can be assumed to be negligible if the panels are mounted at least $1.25 \mathrm{~m}$ away from the edge, parallel to the roof and no more than $15.25 \mathrm{~cm}$ above the surface ${ }^{15}$. The live load due to maintenance personnel was expected to be already accounted for in the design of the roof itself, as the roof was inspected after the 2009 cyclone.

These loads can significantly add to the loading conditions of a single truss, joist, rafter, decking or other roof components. The location of roof brackets or mounts depends on the 
dimensions of the panels or sub-arrays, and may not coincide with the locations of structural members. In these cases direct attachment to the roof decking is often used, but the strength and reliability of this approach is questionable. We strongly recommend attaching mounts to the roof truss, rafter or joist rather than to the roof deck alone when high wind induced loads are anticipated. We installed the mounting structure to the wooden joists using lag bolts.

Since the roof chosen for installing the PV panels was covered with corrugated steel, two aluminum beams were attached with bolts to the structural members of the roof to help minimize the weight of the mounting structure. Two panels were designed to be attached to those beams using bolts and clamps (Figure 9).

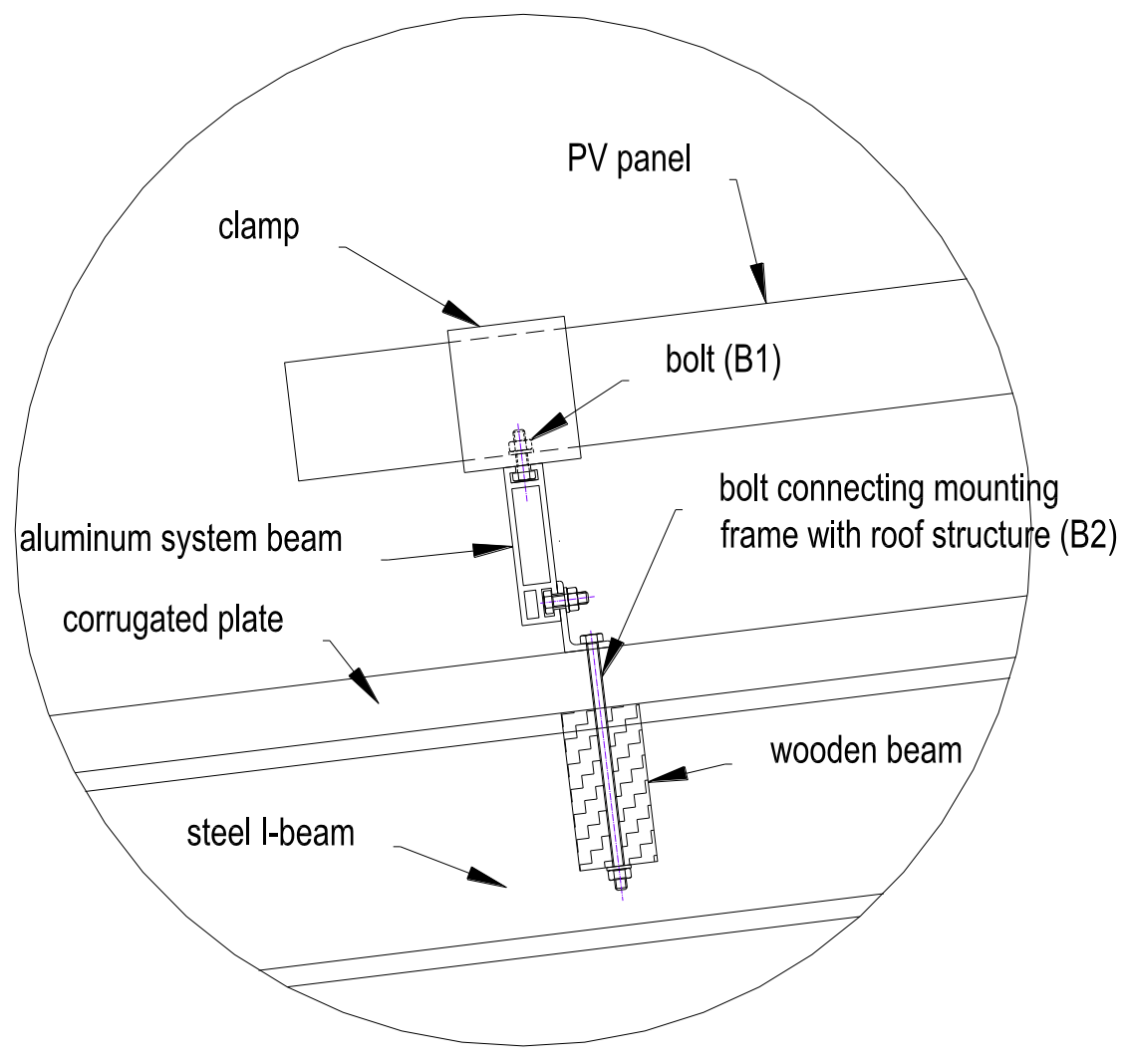

FIGURE 9

A METHOD FOR MOUNTING THE PANELS WAS DEVELOPED TO ENSURE STABLE ATTACHMENT TO THE CORRUGATED METAL ROOF

\section{System Electronics - Security and Safety}

The batteries, charge controller, breakers and relay were contained within a wooden battery box built by a local carpenter in Kianjavato (Figure 10). Three switches were mounted on the outside of the box due to the delicate nature of the concrete skim on the interior of the building. The doors to this box have padlocks for the security and safety of the students. The battery compartment passively vents away from the classroom. This is a scalable solution to security and safety that can be employed at future sites. 

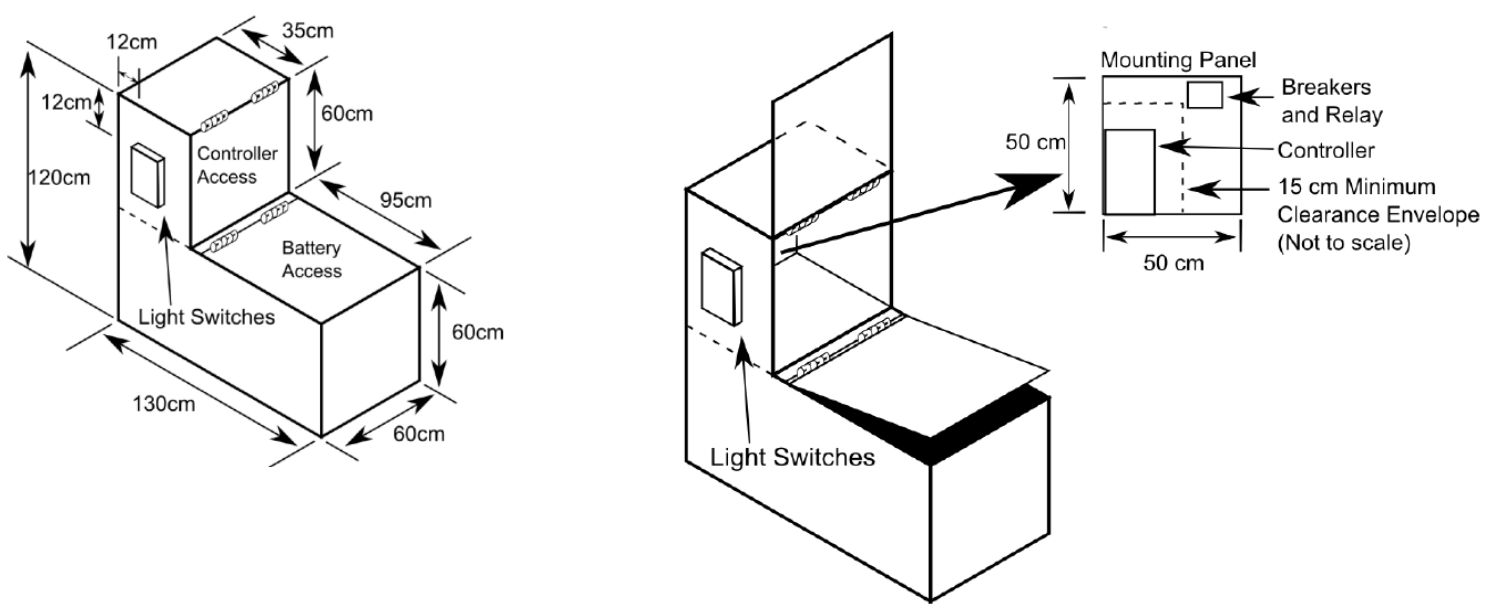

FIGURE 10

A SPECIFIC DESIGN FOR THE BATTERY/CONTROLLER BOX WAS DEVELOPED SO IT COULD BE EASILY ASSEMBLED BY A LOCAL CARPENTER.

\section{Monitoring}

A monitoring system must ensure that the system is operating properly, assess performance of the components, identify faulty components and help suggest improvements to future systems ${ }^{16}$. Long and short term monitoring will be employed to measure the overall success of the installation. Both quantitative and qualitative metrics have been developed to accurately represent the interaction between the system and the community. Our three general metrics for success were availability of sunlight, system functionality, and benefit to the community.

We expected that sunlight would be available daily, but the extent of availability will be important to future projects. Since we decided to design conservatively around the lowest average daily solar insolation measured in 2011-2012, total power production may be underestimated when averaged over years of use. This knowledge will improve the economics, efficiency and potential capacity of future systems, so we will continue to collect data from the weather station.

Functionality monitoring will occur in real-time, and be recorded and logged to provide longterm data for optimizing new installations. Short-term metrics will be applied to daily and weekly operation. Long-term metrics will determine if system degradation is occurring. Designated school staff will observe the meters screen of the charge controller and record general cloud conditions on a daily basis. This will ensure proper functionality and demonstrate to Kianjavato primary school students the correlation between weather and energy production. The students will also become involved in these activities as they become more familiar with the equipment. In addition, the charge controller records watt-hours, amp-hours, and peak watts, and then summarizes these as averages and stores all data on a daily, monthly and lifetime basis. These can be viewed on the charge controller and manually recorded as solar intensity and temperature data. At the end of each day of use, school staff was instructed to record data from the charge controller meters in a format provided by EWB-NU. It is not likely the system will be operating under peak sun conditions at the end of the day of use, so teachers will take periodic measurements throughout the day. They will record time and date, voltage, current and power 
into the controller, amp hours and kilowatt hours produced during the day, "time online" (how long the system has been producing power for the day), general cloud cover estimate (a scale of 1 to 10) and voltage of the battery array. The battery will be monitored by recording voltage readings from the charge controller and confirmed by an external voltmeter measurement. As an additional way of monitoring the batteries, specific gravity will be measured yearly with a hydrometer. This activity is consistent with the EWB-USA Energy Resource Guidelines ${ }^{17}$.

The benefit to the community will be measured both qualitatively and quantitatively. Light intensity sensors within classrooms will continue to collect data. We expect an increase in recorded light intensity by 53.8-107.6 lux during the lifetime of the system. Success will be determined by our ability to meet this goal through the analysis of long-term data. Responses by the teaching staff will constitute the qualitative aspect of our monitoring plan. Teachers will report attendance, trends in student performance and the number of hours of use the building receives by extending nightly hours. Ultimately, we will be successful if the building receives $30 \%$ more use than before installation.

\section{IMPLEMENTATION}

In the months before installation, EWB-NU constructed a prototype solar panel system in the U.S. Specifications of components were matched as closely as possible to the system to be built in Kianjavato. In doing so, we gained an understanding of the potential difficulties faced during construction in Madagascar, as well as the proper installation sequence and the tools required.

The PV solar system was constructed and installed at the primary school in Kianjavato by a team of six during May 2012. After installation was complete, teachers at the Kianjavato primary school were educated on proper operation and maintenance of the system (Figure 11). Neither MBP nor the community, however, were allowed to help install electrical components of the system as the team did not know each individual's level knowledge of solar power systems prior to this education session. Instead, the community assisted with the installation of the support structure on the roof, as they had experience working with corrugated metal roofs. All necessary equipment and materials were bought in Madagascar with the exception of some monitoring equipment used to assess this pilot installation. By doing so, we ensure that replacement parts can be purchased by those in Madagascar, rather than having to ship them parts from out of the country. The owner of the solar panel system, Chef ZAP, will be able to maintain and replace components in the system for years after our direct involvement has ended. This design consideration is also a requirement of EWB-USA. 


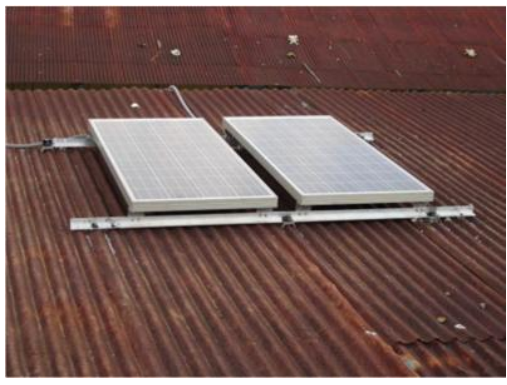

A

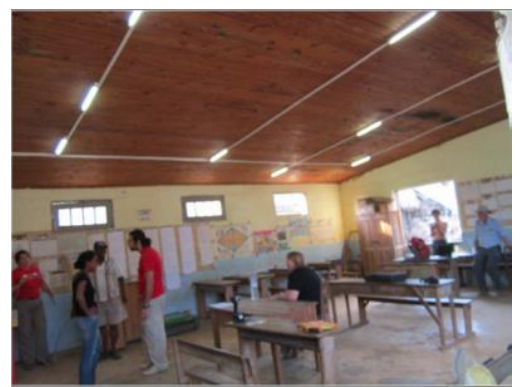

B

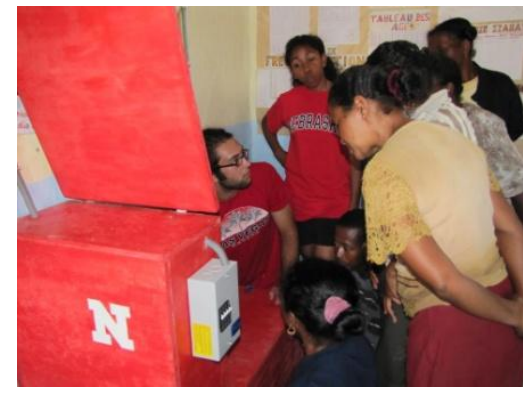

$\mathrm{C}$

FIGURE 11

A) THE PANELS WERE ROOF MOUNTED. B) THE LIGHTS WERE MOUNTED TO THE CEILING OF THE CLASSROOM. C) TEACHERS AT THE SCHOOL WERE EDUCATED AFTER THE INSTALLATION ON METHODS FOR PROPER OPERATION AND MAINTENANCE.

\section{In-Country Changes to Equipment}

Improvised changes to the designed system were necessary for a variety of reasons. The first change was made because Tenesol@ did not have the $32 \mathrm{~W}$ bulbs or fixtures in stock when we arrived. The lights and fixtures that were available were $13 \mathrm{~W}$ fluorescent kits. Unfortunately, these came without technical specifications on number of lumens that would be emitted per bulb. We then had to assume that the amount of lumens per watt was nearly the same for both types of bulbs. Thus, ten $13 \mathrm{~W}$ fluorescent lights were used providing a total system wattage of $130 \mathrm{~W}$ instead of $128 \mathrm{~W}$. The system autonomy plots have been re-calculated for due diligence and the outcome was found to be not significantly different from the results displayed in Figure 6. Specifically, the system autonomy was considered acceptable because, even with seven consecutive days of solar insolation one standard deviation below the average cloudy day, the batteries will not discharge below $50 \%$ by the end of the week.

The second change also came after meeting with personnel at Tenesol®. The planned implementation used conventional screws and bolts to mount the solar panels to the aluminum frame. The salesmen at Tenesol ${ }^{\circledR}$ introduced security bolts to us, and those were used to deter theft instead of conventional bolts for panel mounting.

The third change came after meeting with Chef ZAP. Originally the panels were to be mounted on the northern central part of the roof for easy access and less shading. However, Chef ZAP informed us of minor damage exacerbated by rainfall in this portion of the roof. But because the damage was confined to only a small area, it was decided to mount on an unaffected area higher up on the roof. EWB-NU recalculated solar shading using the Solar Pathfinder ${ }^{\circledR}$ and it was determined to be 5\% (Figure 12). The PV array was thus mounted in the southeastern corner of the roof without delay. 


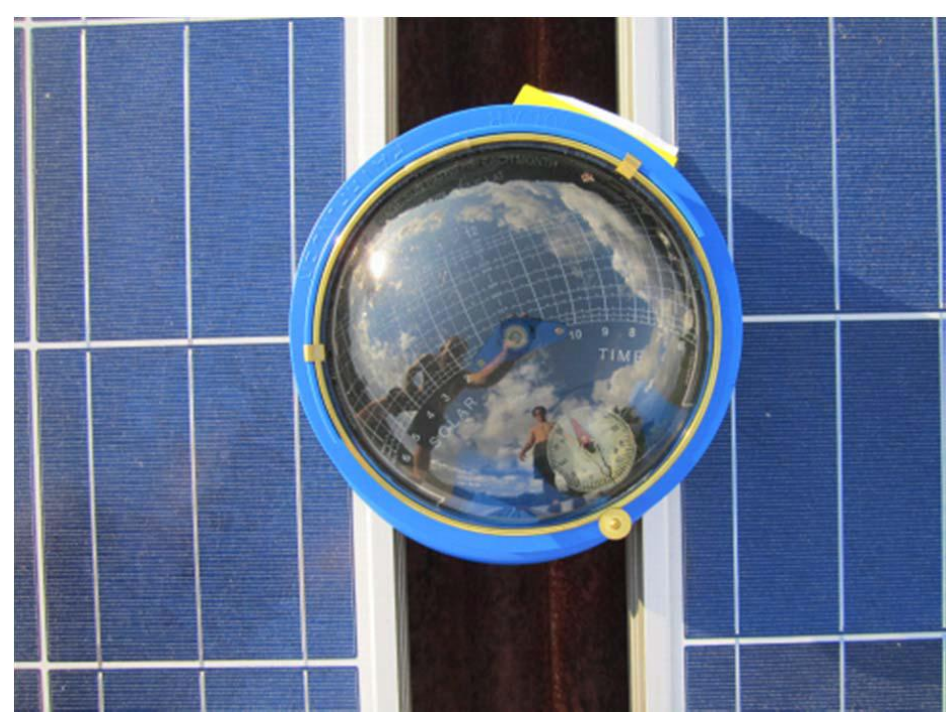

FIGURE 12

A SOLAR PATHFINDER ${ }^{\circledR}$ WAS USED TO VERIFY SOLAR SHADING MEASUREMENTS

ON THE PV ARRAY AFTER INSTALLATION

The fourth change was also made after meeting with Chef ZAP. For the planned implementation, the grounding rod was going to be buried off of the north western point of the building to be nearer to the circuit box, thus minimizing the amount of wire needed. Chef ZAP had concerns about theft of the copper rod from an obvious location near the school entrance. We decided instead to ground the system off of the southeastern point of the building near Chef ZAP's home so he could, in effect, guard both the solar panels and the grounding rod.

The fifth change was to mount the switches onto the battery box instead of the wall. This was a small change which resulted in a modular system electronics box design, beneficial to future projects. The final equipment list used in the implementation is shown in Table III.

\section{CONCLUSION}

During this pilot project, the most important lessons were learned from working within a difficult engineering setting. In-country supplies, such as lights, are not consistently available, theft prevention is essential and changes to the best design are inevitable. Building a prototype system in the U.S. prior to travel provided the necessary experience to construct during the time we had in Madagascar. The post-implementation reporting provided for knowledge transfer to future designs and implementations.

The pilot installation is considered successful from the implementation standpoint. Monitoring will confirm the utility and performance of the system. This project also represents a unique model in the dual promotion of conservation and education through humanitarian efforts. Students have learned to gather data, design and construct off-grid solar power installations as well as the challenges associated with implementations in developing countries. 
International Journal for Service Learning in Engineering Vol. 8, No. 2, pp. 24-42, Fall 2013

ISSN 1555-9033

TABLE III

FINAL EQUIPMENT LIST

\begin{tabular}{lcccc} 
Item & Quantity & $\begin{array}{c}\text { Unit } \\
\text { Cost }\end{array}$ & $\begin{array}{c}\text { Total } \\
\text { Cost }\end{array}$ \\
\hline PV System - Basic Components & & & & \\
\hline PV Modules-Tenesol 1300 135W 12V & 2 & $\$ 440.58$ & $\$ 881.16$ \\
Virio Batterie Solaries - 100 Ah 12V & 2 & $\$ 385.80$ & $\$ 771.60$ \\
Controller-Schneider Xantrex XW-MPPT60-150 & 1 & $\$ 540.00$ & $\$ 540.00$ \\
Lights-13W 12V Fluorescent & 11 & $\$ 64.06$ & $\$ 704.66$ \\
Subtotal & & & & $\$ 2,897.42$
\end{tabular}

Roof Mounting

\begin{tabular}{|c|c|c|c|c|c|}
\hline Aluminum angle stock $(40 \times 40 \times 4)-10$ meters & 10 & $\$$ & 11.35 & $\$$ & 113.50 \\
\hline Corrugated roof clamp & 6 & $\$$ & 5.33 & $\$$ & 31.98 \\
\hline Security bolts & 24 & $\$$ & 1.82 & $\$$ & 43.68 \\
\hline Lag bolts & 6 & $\$$ & 1.37 & $\$$ & 8.22 \\
\hline Silicon caulk (tube) & 2 & $\$$ & 7.73 & $\$$ & 15.46 \\
\hline Subtotal & & & & $\$$ & 212.84 \\
\hline
\end{tabular}

Wiring, Supplies \& Monitoring

\begin{tabular}{|c|c|c|c|c|c|}
\hline Circuit breaker $30 \mathrm{amp}$ & 2 & $\$$ & 14.17 & $\$$ & 28.34 \\
\hline Circuit breaker $20 \mathrm{amp}$ & 3 & $\$$ & 14.17 & $\$$ & 42.51 \\
\hline Circuit breaker $10 \mathrm{amp}$ & 5 & $\$$ & 13.72 & $\$$ & 68.60 \\
\hline Negative bus bar, white & 2 & $\$$ & 14.40 & $\$$ & 28.80 \\
\hline Breaker bus bar & 1 & $\$$ & 17.61 & $\$$ & 17.61 \\
\hline Relay 781XAC-12D & 1 & $\$$ & 10.80 & $\$$ & 10.80 \\
\hline Relay socket 70-781D5-1A & 1 & $\$$ & 9.87 & $\$$ & 9.87 \\
\hline Switch box & 2 & $\$$ & 46.08 & $\$$ & 92.16 \\
\hline $2.5 \mathrm{~mm}^{2}$ wire -100 meter coils & 3 & $\$$ & 59.78 & $\$$ & 179.34 \\
\hline $6 \mathrm{~mm} 2$ wire - 100 meter coils & 1 & $\$$ & 132.85 & $\$$ & 132.85 \\
\hline Interior conduit (10x30) - 2 meter lengths & 20 & $\$$ & 3.96 & $\$$ & 79.20 \\
\hline Outdoor conduit - 50 meter lengths & 1 & $\$$ & 37.49 & $\$$ & 37.49 \\
\hline Conduit clips (100 count) & 1 & $\$$ & 15.46 & $\$$ & 15.46 \\
\hline Grounding rod & 1 & $\$$ & 11.59 & $\$$ & 11.59 \\
\hline Grounding rod wiring clamp & 1 & $\$$ & 2.46 & $\$$ & 2.46 \\
\hline Spare florescent light bulbs & 2 & $\$$ & 5.80 & $\$$ & 11.60 \\
\hline Black mat spray paint (cans) & 3 & $\$$ & 14.01 & $\$$ & 42.03 \\
\hline Screws $(\mathrm{kg})$ & 1.3 & $\$$ & 1.59 & $\$$ & 2.07 \\
\hline Funnel & 1 & $\$$ & 2.61 & $\$$ & 2.61 \\
\hline Vaseline & 1 & $\$$ & 0.72 & $\$$ & 0.72 \\
\hline Subtotal & & & & $\$$ & 630.25 \\
\hline \multicolumn{6}{|l|}{ Battery Box } \\
\hline Plywood (1.2x2.4x20) & 2 & $\$$ & 42.51 & $\$$ & 85.02 \\
\hline White spray paint (cans) & 2 & $\$$ & 14.01 & $\$$ & 28.02 \\
\hline Red paint (1 liter) & 1 & $\$$ & 5.70 & $\$$ & 5.70 \\
\hline Hinges & 4 & $\$$ & 2.46 & $\$$ & 9.84 \\
\hline Paint brushes & 2 & $\$$ & 4.69 & $\$$ & 9.38 \\
\hline Labor - carpenter (days) & 1 & $\$$ & 3.62 & $\$$ & 3.62 \\
\hline Subtotal & & & & $\$$ & 141.58 \\
\hline
\end{tabular}




\section{Acknowledgment}

We wish to acknowledge to Dr. Edward Louis of the MBP for allowing the team to stay and work at Kianjavato Ahmanson Field Station. Zoelitiana Ndrianajasoloarivony translated Malagasy while in-country. Dr. Michael Jarzab performed the structural analysis and mounting detail. Brandon Riehl generated the relay diagram and electronics box diagram. Thanks to Jon Dixon of Dixon Power Systems for his mentorship.

\section{REFERENCES}

\footnotetext{
${ }^{1}$ International Energy Agency, World Energy Outlook 2012, “Global status of modern energy access,” accessed April 2013.

${ }^{2}$ F.S. Javadi, B.Rismanchi, M.Sarraf, O.Afshar, R.Saidur, H.W.Ping, N.A.Rahim, "Global Policy of rural electrification," Renewable and Sustainable Energy Reviews, vol. 19, (2013), 402-416.

${ }^{3}$ United States Census Bureau, accessed via Google (April 2013)

4 The World Bank, "Madagascar Population," accessed via Google Public Data (April 2013)

5 The World Bank, "Madagascar Overview," accessed online (April 2013)

${ }^{6}$ Google Maps, "Madagascar," accessed online (May 2013)

${ }^{7}$ Google Earth, "Kianjavato," accessed online (May 2013)

${ }^{8}$ Kaygusuz, K., "Energy services and energy poverty for sustainable rural development," Renewable and Sustainable Energy Reviews, vol. 15 (2011), 936-947.

${ }^{9}$ NASA, Surface Meteorology and Solar Energy (October 2011)

${ }^{10}$ Solar Energy Institute, "Photovoltaics: Design and Instalation Manual," (2007)

${ }^{11}$ Bhusal, P., Zahnd, A., Eloholma, M., Halonen, L., "Replacing Fuel Based Lighting with Light Emitting Diodes in Developing Countries: Energy and Lighting in Rural Nepali Homes," The Illuminating Engineering Society of North America, Leukos vol. 3 no. 7 (2007), 277-291.

${ }^{12}$ Osterhaus, Werner, "Office Lighting: A Review of 80 Years of Standards and Recommendations," Proceedings of the IEEE Industry Applications Society Annual Meeting (1993)

${ }^{13}$ Holophane, "Lighting Fundamentals" (2006) accessed online at: http://www.lightingassociates.org/i/u/2127806/f/tech_sheets/Lighting_Fundamentals_1.pdf

${ }^{14}$ Huacuz, J., Flores, R., Agredano, J., Munguia, G, "Field performance of lead acid batteries in photovoltaic rural electrification kits," Solar Energy vol. 55 no. 4 (1995), 287-299

${ }^{15}$ Barkaszi and O’Brien, Florida Solar Energy Center, BEW Engineering, "Wind Load Calculations for PV Arrays," Solar American Board for Codes and Standards Report (2010)

16 Thevenard, Didier, Michael M. D. Ross, and Gordon Howell. "A Checklist for PV System Monitoring". Renewable Energy Technologies in Cold Climates: Proceedings of the 24th Annual Conference of the Solar Energy Society of Canada, Montréal, Québec, Canada (May 4-6, 1998), 273-278.

17 EWB-USA, "Energy Resource Guidelines" (September 2006)
} 